\section{The role of external partners in regional cooperation projects in the Middle East}

\section{Raphael Bar-El and Miki Malul}

$\mathrm{R}$ egional cooperation projects, including those in the Middle East, are expected to benefit its direct participants. They may also "spill over" to positively affect others. In this article we consider two types of spill-over or externality effects, namely well-known economic benefits, such as employment and income effects, and benefits that are not necessarily measurable in pure economic terms, such as regional stability, the easing of social tensions, and the diminution of international conflicts. ${ }^{1}$ Project justification is based on the expected net benefits brought to the direct participants, to the region, and to the world as a whole. But if the decision is taken only by the direct participants, even if by public bodies, market failure may result inasmuch as potentially positive external effects are not part of the decisionmaking calculus. This might justify external involvement. This article examines types of regional cooperation projects in the Middle East that call for such an external involvement, specifically the involvement of bodies outside the region (countries or nongovernmental organizations).

Benefits of Middle Eastern regional cooperation have been categorized into three groups: economies of scale, complementarities between production factors, and externalities. ${ }^{2}$ For example, a statistically significant, positive correlation between the Palestinian unemployment rate and the number of suicide, shooting, and total attacks carried out has been found. A cooperation project that reduces the unemployment among Palestinians would create a positive sociopolitical externality that benefits the region, but a private investor would not be expected to take this into account. ${ }^{3}$ History provides some encouragement for believing that an investment in joint projects can be successful either as a part of a more comprehensive, that is, macro, framework or as a stand-alone effort that can grow into a much larger cooperative process. ${ }^{4}$ This means that such projects possess positive externalities. An example of planting such seeds of cooperation, which gradually spread throughout an entire conflict arena and achieved desirable outcomes, is the formation of the coal and steel community in France and Germany in the 1950 s. This cut through the centuries-old conflicts of these two countries and their various allies. A small initial step soon led to other small cooperative steps, for example, the establishment early on of Euratom. These and subsequent other small yet incrementally larger steps eventually led to the adoption, more recently, of a common currency across much of Europe along with the beginnings of banking and political union, culminating in the development of a proposed constitution covering the union of 27 states.

In another example, small but effective cooperative efforts are slowly taking place between North and South Korea. First proposed at the 1997 Peace Science Society International conference in Sydney, Australia, a small-scale cooperative tourism project in the Demilitarized Zone was put forth by Cornell University researchers as a modest way to begin to reduce the likelihood of potential conflict. ${ }^{5}$ Efforts along these lines began in 1998 when a contract to establish such a project was signed by the two adversaries. Subsequently, this has lead to additional steps that have significantly reduced tensions between these two nations.

Using an interregional input-output framework, it has been suggested that projects relating to Palestinian sectors of banking and construction are expected to generate a higher multiplier to the region. ${ }^{6}$ This multiplier effect is part of the externalities that stem from the project. Even though joint projects can benefit the region, there are many constraints that can prevent their implementation, such as gaps in economic structure between the countries, gaps in social structure and security considerations.

It can be expected that a large portion of the projects will not receive financing from the business sector because they do not internalize the externalities (assuming now that all are positive externalities) ${ }^{8}$ Therefore it is possible that the benefits to the Middle East region as a whole or to the world exceed the regional or world costs, even when private business benefits are less than private business costs. That entrepreneurs will not invest in such cases is the result of market failure from the region's point of view. Thus the role of countries involved in project financing amounts to maximizing the region's (or world's) welfare. It should be noted that when the partners of a cooperation project are countries and not individuals, the countries involved internalize part or all of the positive externalities (they still do not internalize the externalities that affect other countries), so they tend to behave in a more efficient way than the private sector. Furthermore, in certain projects, the cost-benefit for the country involved may be negative while the cost-benefit from the regional/world point of view is positive: the country fails to internalize the externalities that other countries in the region (or even the rest of the world) enjoy. Again, the role of other countries in project financing becomes crucial. There are therefore two levels of market failure in financing joint projects in the Middle East: the first concerns the asymmetry between private investors and the countries involved; the second that between the countries involved and other countries that can benefit from the project.

\section{Hypothesis and data}

If positive externalities exist at the world level, the involvement of partners from outside the Middle East is an efficient instrument for the solution of regional market failures. External participants, mostly European and the United States, are expected to be attracted by the benefits, both economic and social, that may be provided by the projects with externalities. In practical terms, we do not expect the involvement of external partners to be the same in all types of cooperation projects, but we do expect such involvement to focus mostly on those projects that suffer disproportionately from 
market failure and therefore would improve the world's welfare.

A data base compiled by Israel's Ministry of Finance, and further developed by the Ministry of Regional Cooperation, includes 489 regional cooperation ideas which have been raised since $1993 .^{9}$ Our analysis is based on the 231 projects for which the data is complete. While these are probably not a representative sample of the 489 projects, we nonetheless believe that they are well suited for our analysis. The reason is that the projects for which we lack data are probably those that did not reach an appropriate stage of maturity and therefore information about them has not yet been collected. They may still be under consideration, or may have been considered and rejected.

A number of projects relate to a single country, but most of them involve at leas two Middle Eastern countries. They are Israel, Jordan, Egypt, Lebanon, Syria, and the Palestinian Authority. The data set includes projects that cover a wide variety of areas of cooperation and at various stages of processing. About ten percent of the projects are still in the phase of idea consideration, with no active steps taken yet for implementation. These include many desalination projects, tourism ideas, and research projects. About 20 percent are at the stage of feasibility studies and planning, such as various large-scale Jordan Rift Valley projects (including the Red Sea-Dead Sea canal project), industrial zones, and a joint Israeli-Jordanian airport. Another 35 percent are in active implementation, such as the construction of industrial parks, and some research projects and ecology projects, and the remaining 35 percent of the projects have already been implemented, such as trade agreements, air transport agreements, and energy agreements.

The variables

External partnership, the variable to be explained in our model, is defined as a financial cooperation partner external to the Middle East region. ${ }^{10}$ This may be a government (usually from Europe or the United States) or a nongovernmental organization. Explanatory variables are specified according to the types of projects. These are defined according to a classification made on the same data source, using three main variables: sector, extent, and intensity of cooperation. ${ }^{11}$ For each, we compare the level of externalities envisioned or achieved with the share of projects having external partners. We expect to find a higher share of external partners at higher levels of (expected) externalities. We present here the two groups of variables: those that define the typology of projects, and those that measure externalities.

\section{Classification}

Sectors of cooperation are classified into three main groups. First, infrastructure projects include the building of bridges, railways, airports, seaports, and roads, as well as energy, sewage, water, communication, employment parks. Second, economic activities projects include business agreements, agriculture, and tourism. And third, public service projects include mostly environmental projects, as well as education, research, health, and general framework agreements.

Extent of cooperation reflects the number of countries involved. First, single country projects count only on support from other countries but without actual cooperation in their implementation. Second, bilateral projects involve two countries. Third, multi-lateral projects involve three or more countries in the cooperation project.

The intensity of project cooperation is defined as the level of "jointness" with which the project is run. First, in low-intensity projects cooperation takes the form of mere coordination of actions, without active cooperation. Those may be projects that are conducted by one of the countries for its own interests, but that may affect another country, such as the building of dams, the development of tourism structures in neighboring regions, the installation of basic infrastructures in one country such as a neighboring sea port, and environmental projects in a neighboring region. Second, medium-intensity projects are based on agreements between the countries, but the implementation is mostly performed by the countries separately. Projects in this category include the creation of joint frameworks in various fields (such as joint investment funds, and joint professional organizations and forums), the signing of formal agreements (such as trade, air transport, and water distribution agreements), and the implementation of training programs (mainly in the field of agriculture) Third, high-intensity projects are actively jointly planned or managed. Such projects may be joint industrial parks, joint infrastructure projects (such as bridges between two countries, transregional roads), joint industrial enterprises, environmental care, and administration of water distribution.

\section{Externalities}

Externalities are classified as macroeconomic or sociopolitical. ${ }^{12}$ The first is defined as the gap between the regional or global impacts of a project and its microeconomic viability; the second is defined as the gap between the same regional or global impacts and the feasibility of the project in terms of sociopolitical constraints (and detailed below). All variables are measured on a scale of 1 (low) to 5 (high), as evaluated by a group of experts. This group included 12 experts from a wide variety of fields. All were professionals involved in the field of economic cooperation in the Ministry of Regional Development and related ministries, professors that dealt with regional development, and economic development planners from private companies. In addition, some of the evaluations were based on a detailed description that accompanied most project proposals (including technical, economic, and financial analyses). Most of this information came from government ministries from Israel, Jordan, the Palestinian Authority, and Egypt.

Microeconomic viability is measured in terms of the evaluation of expected return for capital investments, or business profitability. For public projects that are not 
expected to be evaluated in terms of business profitability, microeconomic viability is evaluated in terms of public utility achieved by given amounts of investment.

Regional (or global) impacts are defined as benefits received, or losses incurred, by the region (or the world as a whole) in consequence of the existence of a cooperation project. Such impacts may be of an economic nature, but they can also be viewed in terms of a social nature.

Macroeconomic externalities (MEE) are then defined as the gap between regional (or global) impact and microeconomic viability. The difference is the extra benefit not perceived within the project itself, but received by the economy of the region or the world as a whole. Actually, economic policy should consider the macroeconomic benefits as its major objective and provide incentives to all projects that create externalities. A project with a low level of microeconomic viability may not be implemented because its benefits to the investor are low, but if it has a high level of regional or global impact, public policy and external bodies should support it because of the benefits it brings to the region and to the world as a whole.

Feasibility is the degree to which the project responds to various constraints, both economic and noneconomic, that may inhibit or constrain the ability to cooperate. The evaluation of the feasibility of a cooperation project reflects the influence of such constraints and mostly measures the coherence of the project with the existing social and economic regimes in the partner countries, the intensity of personal contacts needed in the implementation of the project, the potential access to resources, and the potential for conflicts with other factors.

Finally, we define sociopolitical externalities (SPE) as the gap between the regional impact, or the benefits of the project for the region, and the feasibility level of the project. The difference measures the cost of socioeconomic constraints for cooperation in terms of global losses to the region as a whole and to other countries. In other words, a project with a low level of feasibility because of socioeconomic constraints may not be implemented in spite of the potential for long-term benefits and for contributing to the development of the region and to global stability. Projects in which this difference is large should be analyzed in depth in order to identify the constraints on their feasibility, and attempts should be made to find as many solutions as possible for these constraints. In this case, public policy is required for the solution or at least the alleviation of the constraints. The participation of external partners in such projects may alleviate to a certain extent the effects of such constraints by diminishing the intensity of direct contacts between countries in the region and therefore decreasing this type of market failure.

\section{Results}

To illustrate the types of projects contained in the data set, we present a short description of two projects. First, the Red Sea-Dead Sea Peace Conduit is a pipeline designed to conserve the Dead Sea by conveying water from the Red Sea to the Dead
Sea. At the Dead Sea, desalination plants can be constructed to provide drinking water to populations residing in Jordan, Israel, and the Palestinian Authority. The Peace Conduit project was presented jointly by the governments of Jordan and Israel at the Johannesburg Summit on Sustainable Development in September 2002. The World Bank considered the financing of a comprehensive feasibility study and Environmental Impact Assessment for this project. The project could bring direct economic benefits such as water desalination. The economic feasibility of the project is graded as medium (3) mainly due to the fact that this project requires a big investment and may be substituted by local desalination plants, achieving similar results at lower costs. However, the externalities are relatively high: the economics externalities are graded as 2 (on a scale of -4 to 4 ) as are the sociopolitical externalities. ${ }^{13}$ This stems from the fact that such a project could boost the tourism in the region, which could generate an additional economic value (externality) to each country and to the region. As for the sociopolitical externalities, the cooperation that this project requires from all of the parties could mitigate the conflict and could set a price on conflict: after the project is implemented, any conflict resurgence in the region would require the cost of abolishing the project.

Second, the establishment of safe passage routes between Gaza and the West Bank was stipulated in Annex I of the 1995 Israeli-Palestinian Interim Agreement on the West Bank and Gaza Strip. These routes are designed to ensure free transfer of people and goods between the two sections of the Palestinian Authority, without jeopardizing security in Israel. This project was assigned a low grade for sociopolitical externalities because the safe passage was designed in a way so that no interactions between Palestinians and Israelis would occur: the passage would be isolated and passengers would start their trip in Gaza and end it in the West Bank without stopping in Israeli territory. As for economics, it generates medium levels of externalities in that it could stimulate more efficient economic resource allocation in the Palestinian Authority.

Table 1 shows the distribution of the projects according to the various attributes. The first letter in each group represents the sector type: I - infrastructure; E economic activities; and $\mathrm{P}$ - public services. The second letter represents the extent of each project ( $\mathrm{S}$ - single country; B - bilateral; $\mathrm{M}$ - multilateral), and the last letter represents the intensity of cooperation ( $\mathrm{L}$ - low; $\mathrm{M}$ - medium; $\mathrm{H}$ - high).

The largest number of projects are ISL (infrastructure; single-country; low intensity; 15.15 percent of all 231 projects), IBH (infrastructure; bilateral; high intensity; 12.12 percent), IMH (infrastructure; multilateral; high intensity; 9.96 percent), and PMH (public sector; multilateral; high intensity; 9.09 percent). Together they account for about 50 percent of all the projects.

In Table 2, we examine the extent to which the participation of external partners is related to the stage of implementation of the project. About half of the privately financed projects do not pass the stage of feasibility study. This is understandable if private investors cannot internalize the externalities and therefore cannot find an economic justification for the project. When the countries directly involved finance 
Table 1: Project distribution by attributes (\%)

(in parentheses: percentage of projects implemented or in active implementation)

$\begin{array}{lcllll}\text { ISL } & 15.15(71) & \text { ESL } & 3.90(100) & \text { PSL } & 2.60(83) \\ \text { ISM } & 0.43(100) & \text { ESM } & 0.00(-) & \text { PSM } & 0.00(-) \\ \text { ISH } & 0.00(-) & \text { ESH } & 0.00(-) & \text { PSH } & 0.00(-) \\ \text { IBL } & 3.46(67) & \text { EBL } & 0.43(0) & \text { PBL } & 0.87(100) \\ \text { IBM } & 4.33(100) & \text { EBM } & 3.46(71) & \text { PBM } & 1.30(67) \\ \text { IBH } & 12.12(48) & \text { EBH } & 4.76(72) & \text { PBH } & 6.93(43) \\ \text { IML } & 0.87(100) & \text { EML } & 0.00(-) & \text { PML } & 0.00(-) \\ \text { IMM } & 5.19(89) & \text { EMM } & 4.33(75) & \text { PMM } & 5.63(93) \\ \text { IMH } & 9.96(64) & \text { EMH } & 5.19(70) & \text { PMH } & 9.09(90) \\ & & & & & \end{array}$

Notes: I - infrastructure; E - economic activities; P - public services; S - single country; B - bilateral; M - multilateral; L - low; M - medium; H - high. For example, $15.15 \%$ of the 231 projects in the data set are single-country, lowintensity, infrastructure projects; of those, $71 \%$ are being or have been implemented, the remainder being in the planning phase.

the project, and can internalize part or all of the externalities, about 70 percent of the projects pass the feasibility test. And when external partners are involved in the financing, about 80 percent of the projects are either implemented or are in the process of implementation: this would be expected if external financiers succeed in internalizing all (or most) of the externalities that the project generates.

\section{The influence of sectors}

From Table 3 we see that the majority of the 231 cooperation projects for which data are available have the participation of external partners. This implies that the international community probably plays an important role in internalizing the extra benefits (or part of them) that stem from the projects. Thus we next examine which share of projects with external partners is associated with which type of project and level of externalities. ${ }^{14}$ We expect to find a higher share of projects with external partners in projects with higher levels of externalities that can be captured (internalized). Table 3 shows that the participation of external international partners in cooperation projects is attracted to sectors with the highest levels of externalities. ${ }^{15}$ Although external partners are found in high proportions in all sectors, their highest
Table 2: Project distribution according to different stages and financing

$\begin{array}{lrcccc}\text { Financing by } & \begin{array}{l}\text { Idea } \\ \text { stage }\end{array} & \begin{array}{l}\text { Feasibility } \\ \text { stage }\end{array} & \begin{array}{l}\text { Implemen- } \\ \text { tation stage }\end{array} & \begin{array}{c}\text { Already } \\ \text { implemented }\end{array} & \text { Total } \\ \text { Private parties } & 11 \% & 36 \% & 32 \% & 21 \% & 100 \% \\ \text { Countries involved } & 13 \% & 17 \% & 36 \% & 34 \% & 100 \% \\ \text { External partner } & 5 \% & 13 \% & 37 \% & 45 \% & 100 \%\end{array}$

Table 3: Externalities and external participation by type of sector, cooperation extent, and cooperation intensity

\begin{tabular}{|c|c|c|c|c|}
\hline & $\begin{array}{l}\text { MEE grade } \\
\text { (s.d.) }\end{array}$ & $\begin{array}{l}\text { SPE grade } \\
\text { (s.d.) }\end{array}$ & $\begin{array}{l}\text { With external. } \\
\text { partner/s }(\%)\end{array}$ & Number \\
\hline \multicolumn{5}{|l|}{ Sector } \\
\hline Infrastructure & $1.06(1.04)$ & $0.33(1.07)$ & 42 & 119 \\
\hline Econ./bus. activity & $0.73(0.86)$ & $0.16(1.02)$ & 52 & 51 \\
\hline Public services & $1.04(0.93)$ & $0.46(1.97)$ & 74 & 61 \\
\hline \multicolumn{5}{|l|}{ Extent } \\
\hline Single country & $0.50(1.06)$ & $0.25(1.08)$ & 41 & 51 \\
\hline Bilateral & $0.97(0.89)$ & $0.32(0.89)$ & 37 & 87 \\
\hline Multilateral & $1.21(0.49)$ & $0.62(1.03)$ & 74 & 93 \\
\hline \multicolumn{5}{|l|}{ Intensity } \\
\hline Low & $0.53(1.04)$ & $-0.23(1.04)$ & 51 & 63 \\
\hline Medium & $0.76(0.86)$ & $0.42(0.89)$ & 67 & 57 \\
\hline High & $1.21(0.90)$ & $0.52(0.99)$ & 48 & 111 \\
\hline Total & $0.96(0.98)$ & $0.31(1.04)$ & 53 & 231 \\
\hline
\end{tabular}

Note: MEE - macroeconomic externality; SPE - sociopolitical externality.

share is in the sector of public services (they participate in 74 percent of all projects in this sector), and in this same sector we also find relatively high levels of both macroeconomic externalities and sociopolitical externalities (MEE grade and SPE grade, respectively).

The sector of economic/business activities (mostly private) shows the lowest level of externalities. In percentage terms, here we find lower levels of external 
participation (52 percent), although higher than in the infrastructure sector (42 percent), but in absolute terms this involves the smallest number of projects (51). This may be explained by a pure business element in the decision of external partners to join cooperation projects. It seems that cooperation projects in infrastructure involve mostly the cooperating countries in the region, and their externalities are constrained more to the region and to a lesser extent to the international sphere.

The influence of the extent of cooperation

As regards the extent of cooperation, in terms of the number of countries involved has a significant influence upon the participation of external partners. A large portion (74 percent) of the multilateral projects tend to be co/financed by external countries, and at the same time we find that these projects have the highest levels of externalities of both types, macroeconomic (1.21) and sociopolitical (0.62). This suggests that the international community sees a relatively high value for projects that create intensive cooperation between and among countries in the region.

Multilateral projects are expected to create relatively high sociopolitical externalities (for example, the joint project creates a common interest in political stability), as well as a potential for economic gain outside the region. Therefore in some projects the profit of private investors or of the countries involved may be negative, while the benefit to the region/world is positive, and therefore external financing is necessary to achieve global efficiency.

\section{The influence of intensity of cooperation}

Finally, with respect to the intensity level of cooperation, we find that projects with the highest levels of externalities (1.21 and 0.52 for MEE and SPE, respectively) are those where the intensity of cooperation is high, e.g., joint management, joint planning of projects. Still, this group attracted the lowest share of external participation ( 48 percent). The reason may be that projects in which direct and intense cooperation between the parties in the Middle East has been possible, the internalization of the externalities has already been made by the parties themselves. In that case, there is a smaller requirement for the involvement of external parties from the international community, since their marginal contribution would be lower.

The contribution of the international community is expected to be much higher in projects with a medium level of cooperation; mostly projects based on agreements between Middle Eastern countries, with only few direct contacts in implementation. Although the level of externalities in these projects is not as high as that of projects with the highest levels of cooperation, it is still quite high and requires external participation for the attainment of maximum global gain. Here we find the highest share of external participation (67 percent).

\section{Conclusion}

The international community - governments and nongovernmental organizations apparently plays an important role in the optimization of benefits from regional cooperation projects in the Middle East. As a general rule, this is done through participation of external partners in the financing (with or without other channels of cooperation) in projects that generate high levels of externalities, both in economic and in sociopolitical terms. This is the case for projects in the public services sector, mainly in multilateral projects involving a few countries in the Middle East and generating quite high levels of externalities.

Still, a direct, linear relationship between the level of externalities and the level of participation of external partners in cooperation projects does not necessarily exist. Some of the potential project externalities are captured (internalized) by the participating countries themselves. This is the case for projects in which the extent of cooperation between the countries is already very high, so that the contribution of external partners is less needed. In other cases, the participation of external parties can be explained by pure business considerations. This is the case for the quite high levels of external participation in private sector projects, or in projects in which only one country of the Middle East is involved, with relatively low levels of externalities.

Notes

Raphael Bar-El and Miki Malul teach at the Department of Public Policy and Administration, School of Management, Ben-Gurion University, Beer-Sheva, Israel, and may be reached atrbarel@som.bgu.ac.il and malul@som.bgu.ac.il, respectively.

1. See Bouillon (2004), Forman, et al. (2000), Isard (2004), and Weede (2004).

2. See Bar-El and Schwartz (2003).

3. Saleh (2004).

4. Isard (2004).

5. Isard and Hara (2002).

6. Malul, et al. (2005).

7. Eken, et.al. (1997), Samara (2000); Dinar and Wolf (1997), Giammusso (1999); Bar-El (2005). 
8. To internalize the externalities means to take into account the size of a project's economic contribution to the community (or the country) as a whole, beyond its pure business benefits to the investor.

9. Due to the closing of the Ministry of Regional Cooperation, the data set was last updated in 1999. Therefore some of the information about the projects is missing.

10. While the extent of external finance differs for each project, data is lacking to specify the exact amounts.

\section{See Bar-E1 (2005).}

\section{See Bar-El (2005).}

13. All variables are coded as 1 to 5 ; thus differences can range from -4 to +4 .

14. See Bar-E1 (2005).

15. Macroeconomic externalities (MEE) are defined as the gap between the regional (or global) impact and microeconomic viability. For example, if global impact is 4.5 and microeconomic viability is 3, then MEE is coded as 1.5. Similarly, sociopolitical externalities (SPE) are defined as the gap between the regional impact, or the benefits of the project for the region, and the feasibility level of the project.

\section{References}

Bar-E1, R., and Schwartz, D. 2003. "The Potential Effect of Peace on Regional Economic Cooperation in the Middle East." Peace Economics, Peace Science and Public Policy Vol. 9, No. 1, pp. 1-32.

Bar-El, R. 2005. "A Typology of Regional Cooperation Projects.” Jan Tinbergen Peace Science Conference, Amsterdam (27-29 June).

Bouillon, M.E. 2004. "The Failure of Big Business: On the Socio-economic Reality of the Middle East Peace Process." Mediterranean Politics Vol. 9, No. 1, pp. 1-28.

Dinar, A, and Wolf, A. 1997. "Economic and Political Considerations in Regional Cooperation Models." Agricultural and Resources Economics Review Vol. 26, No. 1, pp. 7-22.

Forman, S., Patrick, S., and Salomons, D. 2000. "Recovering From Conflict: Strategy For An International Response.” Center on International Cooperation. New York: New York University.

Eken, S., Helbling, T., and Mazarei, A. 1997. "Fiscal Policy and Growth in the Middle East and North Africa Region." Working Paper, WP/97/101. W ashington, DC: International Monetary Fund.
Giammusso, M. 1999. "Civil Society Initiatives and Prospects of Economic Development: the Euro-Mediterranean Decentralized Cooperation Networks." Mediterranean Politics Vol. 4, No. 1, pp. 25-52.

Isard, W. 2004. "A Jordan/West Bank Development Proposal." Peace Economics, Peace Science and Public Policy Vol. 10, Iss. 2, Article 2.

Isard, W., and Hara, T. 2002. "The Old City of Jerusalem as a Tourist International Magnet: An Initial Proposal for a First Step Cooperation in the Middle East." Peace Economics, Peace Science and Public Policy Vol. 8, No. 4, pp. 46-59.

Malul, M., Mansury, Y., Hara, T., and Saltzman, S. 2005. "An Economic Development Road Map to Promote Israeli-Palestinian Cooperation." Jan Tinbergen Peace Science Conference, Amsterdam (25-27 June).

Saleh, B. 2004. "Economic Analysis of the Palestinian Second Intifada." Ph.D Dissertation. Department of Economics. Kansas State University.

Samara, A. 2000. "Globalization, the Palestinian Economy, and the 'Peace Process'." Social Justice Vol. 27, No. 4, pp. 117-132.

Weede, E. 2004. "The Diffusion of Prosperity and Peace by Globalization." Independent Review Vol. 9, No. 2, pp. 165-186. 